\title{
Evaluation of the effect of lateral soil pressure on cantilever retaining wall with soil type variation
}

\author{
Chetan Sharma ${ }^{1}$, Vijay Baradiya ${ }^{2}$ \\ ${ }^{1}$ (M.TECH. SCHOLAR,IES, IPS ACADEMY INDORE, INDIA) \\ ${ }^{2}$ (ASSO. PROF. IES, IPS ACADEMY INDORE, INDIA)
}

\begin{abstract}
Retaining wall is defined as a structure with a main purpose to prevent lateral movement, retain earth or water and may role to support vertical loads. There are several types of retaining wall and the most common types used are gravity wall, cantilever wall, counterfort walls and buttressed wall. Therefore, a few components need to be used in order to get the objective. As a result, this system can be used for the design of a cantilever retaining wall. Moreover, it saves time in the design with sufficient layout detail of the cantilever retaining wall. Design of cantilever retaining walls involves stability checks for overturning, sliding and bearing. A trial section is assumed and calculations are made for the stability checks. The important parameters involved are unit weight of backfill soil, stem height and concrete type. The base length and it components namely toe land heel lengths, and base thickness are highly dependent upon these factors and vary sharply with stem height. The trial section geometry for a given wall height, soil data and strength of concrete can be examine from these charts and final section profile may be determined within a minimum time. The charts have been prepared for a wide range of values of soil unit weight, moment.
\end{abstract}

Keywords :Retaining wall, overturning, sliding,soil bearing capacity

\section{INTRODUCTION}

The concrete cantilever retaining wall can be defined as a construction of reinforced concrete to support backfill soil by cantilever action. The base slab serves as a permanent support and prevents against overturning and sliding. The cantilevered stem portion is rigid at the bottom and is free at the top. A key can be an option to be installed at the bottom of the base slab. This is to ensure extra safety against sliding. The walls will provide long-standing stability and serviceability. This type of concrete is widely used because of the easiness in construction and cost-effectiveness.

Due to the rapid development of increasingly powerful computers in the last decades, the solution of rather complex multi-phase problems encountered in widely different fields of engineering tasks is feasible nowadays. Nowadays, the numbers of software in the market is growing. Software is developed to help users in making their task easier. We can find different software for different business processes. In Geotechnical Engineering, there are few software that can be bought in the market. For example, Retain Pro, iCadRetaining Wall Software, and many more.

Retaining walls are structures that are used to retain earth (or any other material) in a position where the ground level changes abruptly. They can be of many types such as gravity wall, cantilever wall, counterfort wall and buttress wall among others. The lateral force due to earth pressure is the main force that acts on the retaining wall which has the tendency to bend, slide and overturn it. The present research focuses on designing the cantilever type of wall for overturning, sliding and bearing. The main considerations are the external stability of the section with the help of codal provision i.e IS: 456:2000 Satisfying the external stability criteria is primarily based on the section giving the required factor of safety. The ratio of resisting forces to the disturbing forces is the factor of safety, and this factor of safety should always be greater than unity for the structure to be safe against failure with respect to that particular criteria. Different modes of failure have different factors of safety. In this paper stability check for a cantilever wall is obtained using a computer program that calculates various sections satisfying the stability criteria, according to the height and properties of earth that the wall is required to support.

\section{CANTILeVer Retaining Wall}

The cantilever wall generally consists of a vertical stem, and a base slab, made up of two distinct regions, viz. a heel slab and a toe slab. All three components behave like one-way cantilever slabs: the 'stem' acts as a vertical cantilever above the lateral earth pressure; the 'heel slab' and the 'toe slab' acts as a horizontal cantilever under the action of the resulting soil pressure. The reinforcement detailing is as given in Fig. 1. The weight of the earth retained helps in maintaining the stability of the wall. 


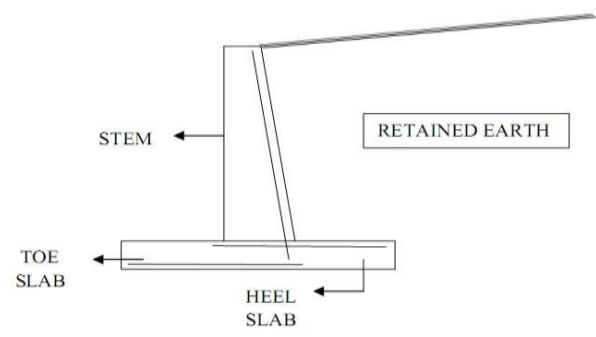

Fig. 1 Cantilever Retaining Wall

\section{Lateral Earth Pressure on Retaining wall}

The main force acting on the retaining wall is constituted by lateral earth pressure which tends to bend, slide and overturn it. The basis for determining the magnitude and direction of the earth pressure are the principles of soil mechanics. The behavior of lateral earth pressure is similar to that of a fluid, with its magnitude pressure increasing nearly linearly with increasing depth $h$ for moderate depths below the surface.

$$
\mathrm{p}=\mathrm{K} \gamma \mathrm{eh}
$$

Where $\gamma e$ is the unit weight of the earth and $K$ is a coefficient that depends on its physical properties, and on whether the pressure is active or passive. The coefficient to be used in Eq. 2.1 is the active pressure coefficient $K a$, in case of active pressure, and the passive pressure coefficient $K p$, in case of passive pressure, Rankine's theory is applied for cohesion less soils and level backfills and the following expressions for Kaand Kpmay be used .

$$
\begin{aligned}
& K_{a}=\frac{1-\sin \varphi}{1+\sin \varphi} \\
& K_{p}=\frac{1+\sin \varphi}{1-\sin \varphi}
\end{aligned}
$$

[2] Where $\varphi$ is the angle of shearing resistance.

When the backfill is sloped, the expression for $K a$ should be modified as follows

$$
K_{a}=\left[\frac{\cos \varphi-\sqrt{\left(\cos ^{2} \theta-\cos ^{2} \varphi\right.}}{\cos \varphi+\sqrt{\left(\cos ^{2} \theta+\cos ^{2} \varphi\right.}}\right] \cos \varphi
$$

Where is the angle of inclination of the backfill, i.e., the angle of its surface with respect to the horizontal.

\section{Stability of a cantilever retaining wall}

Fig. 2 shows a cantilever retaining wall subjected to the following forces:

1. Weight $\mathrm{W} 1$ of the stem $\mathrm{AB}$.

2. Weight $\mathrm{W} 2$ of the base slab DC

3. Weight $\mathrm{W} 3$ of the column of soil supported on the heel slab BC

4. Horizontal force $\mathrm{Pa}$, equal to active earth pressure acting at $\mathrm{H} / 3$ above the base.

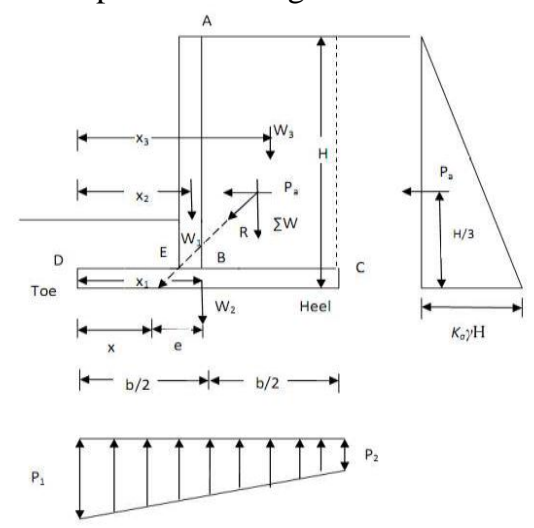

Fig. 2 Schematic Representation of Forces Acting On a Cantilever Retaining Wall 


\section{Analysis Of The Cantilever Retaining WALL}

a) Overturning:

In Fig. 2, the overturning moment, due to active earth pressure, at toe is

$$
\begin{gathered}
M_{0}=P_{a} H / 3=K_{a} \gamma H^{2} / 2 . H / 3 \\
=K_{a} \gamma H^{3} / 6
\end{gathered}
$$

The resisting moment is due to the weights $\mathrm{W} 1, \mathrm{~W} 2$ and $\mathrm{W} 3$, neglecting the passive earth pressure and weight of soil above the toe slab.

Hence,

$$
M_{R}=W_{1} X_{1}+W_{2} X_{2}+W_{3} X_{3}
$$

Hence the factor of safety due to overturning (F1) is given by

$$
F_{1}=\frac{M_{R}}{M_{0}}
$$

A minimum factor of safety due to 2 is adopted.

b) Sliding:

The horizontal force $\mathrm{Pa}$ tends to slide the wall away from the fill. The tendency to resist this is achieved by the friction at the base Fig. 3(b).

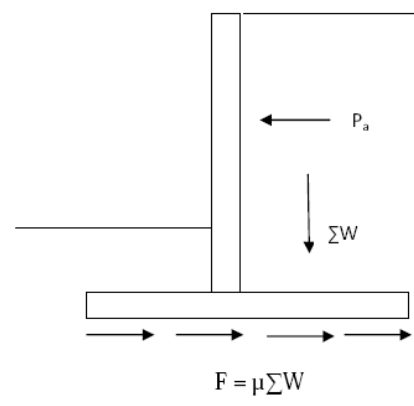

(a)

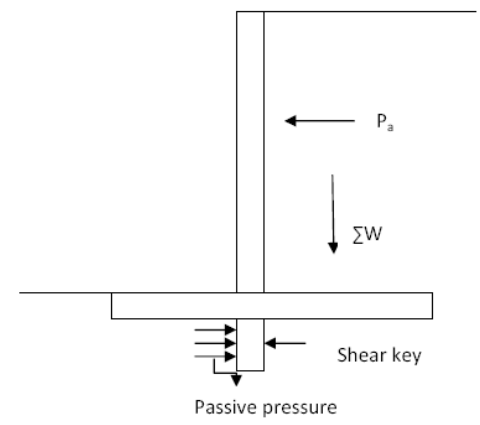

(b)

The force of resistance, $\mathrm{F}$ is given by

Fig. 3 Sliding Of Retaining Wall

$$
\mathrm{F}=\mu \Sigma \mathrm{W}
$$

Where $\mu$ is the coefficient of friction between soil and concrete, and $\Sigma \mathrm{W}$ is the sum of vertical forces.

The factor of safety $F_{2}$ due to sliding is given by

$$
\mathrm{F}_{2}=\frac{\mu \sum \mathrm{W}}{H}
$$

Where $\mathrm{H}=\mathrm{Pa}$.

If the wall is found to be unsafe against sliding, shear key below the base is provided. Such a key develops passive pressure which resists completely the sliding tendency of the wall. A factor of safety of 1.5 is needed against sliding.

\section{c) Soil pressure distribution:}

Fig. 2 shows the various forces acting on the wall. If $\Sigma \mathrm{W}$ is the sum of all vertical forces and Pa is the horizontal active earth pressure, the resultant $\mathrm{R}$ will strike the base slab at a distance $e$, from the middle point of the base. Let $\Sigma M=W 1 \times 1+W 2 \times 2+W 3 \times 3-P a . H / 3=$ net moment at the toe.

Then $x=$ distance of point of application of resultant $=$

$$
\frac{\sum M}{\sum W}
$$

Hence eccentricity $e=b / 2-x$ 
The pressure distribution below the base is shown in Fig. 1. The intensity of soil pressure at the toe and heel is given by

$$
\begin{aligned}
& p_{1}=\frac{\sum W}{b}\left(1+\frac{6 e}{b}\right) \text { at toe } \\
& p_{2}=\frac{\sum W}{b}\left(1-\frac{6 e}{b}\right) \text { at heel }
\end{aligned}
$$

$p$ lat toe should not exceed the safe bearing capacity of the soil otherwise soil will fail. Similarly, $p 2$ at hell should be compressive. If $p 2$ becomes tensile, the heel will be lifted above the soil, which is not permissible. In an extreme case, $p 2$ may be zero, where $e=b / 6$. Hence in order that tension is not developed, the resultant should strike the base within the middle third.

\section{d) Bending failure:}

There are three distinct parts of cantilever retaining wall: the stem $\mathrm{AB}$, the heel slab $\mathrm{BC}$ and the toe slab DE. The stem AB will bend as cantilever, so that tensile face will be towards the backfill. The heel slab will have net pressure acting downwards, and will bend as a cantilever, having tensile face upwards. The pressure distribution will be as shown in Fig. 4. The critical section will be at B, where cracks may occur if it is not reinforced properly at the upper face. The net pressure on toe slab will act upwards, and hence it must be reinforced at the bottom face. The thickness of stem, hell slab and toe slab must be sufficient to withstand compressive stresses due to bending.

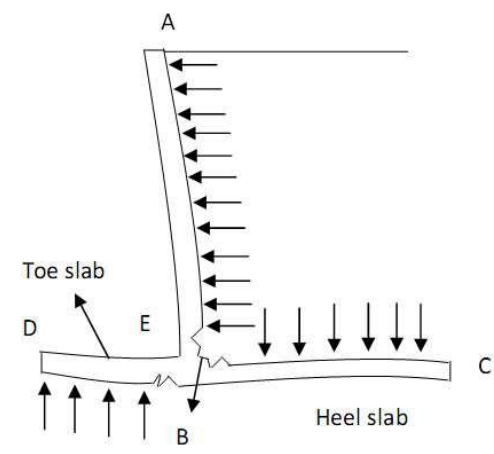

Fig. 4 Bending failure

\section{PROBleM DEFINITION}

The problem under investigation consists of a uniform layer of Elastic material, that is free at it supper surface ,bonded to a non-deformable rigid base and retained a long one of its vertical boundaries by a uniform cantilever wall that is considered to be fixed at the base and to be free at the top. The heights of the wall and soil stratum are considered to be the same, and they are denoted by H.The properties of the soil stratum are de fined by its mass density, shear modulus of elasticity, Poisson's ratio. The properties of the structural wall are defined by its thickness, mass density, moment of inertia, Young's modulus and Poisson's ratio. The scheme of the backfill cantilever wall system examined is shown in Fig. 3.

\section{RESUlt AND DiscusSion}

a) Moments and shears along heel of base slab

The heel is also to be designed as a cantilever. It has both downward pressure (due to weight of soil and self-weight) as well as upward pressure due to soil reaction. However, the net pressure is found to act downward and hence reinforcement is provided at the upper face BC. So that the distribution of moment according to length and the variation of shear force may be calculated and represented by the (a) to (h) graph.

Table.1Used Heightand Density in anlysis .

\begin{tabular}{|c|c|}
\hline Height used & Density used \\
\hline $3.5 \mathrm{~m}, 4 \mathrm{~m}, 5 \mathrm{~m}, 5.5 \mathrm{~m}$ & $\mathbf{1 8 , 2 0 , 2 2 , 2 5 , 2 8 , 3 0 , 3 2 , 4 0}$ \\
\hline
\end{tabular}




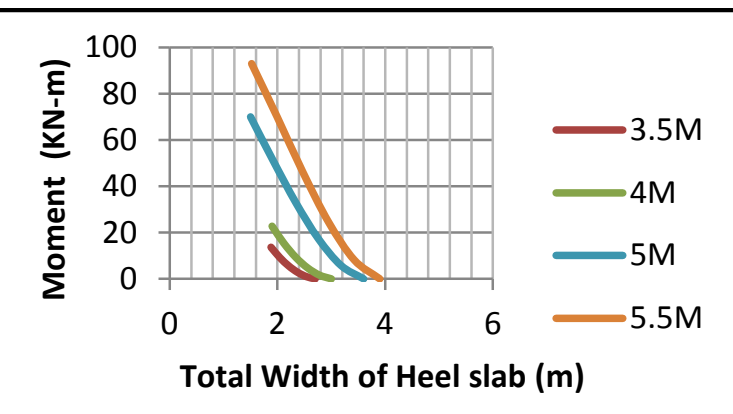

(a)

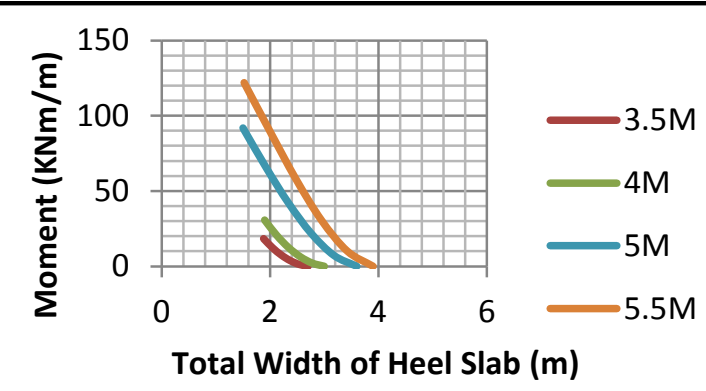

(c)

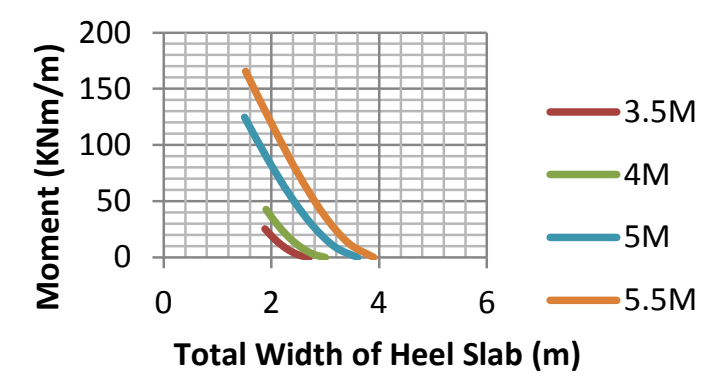

(e)

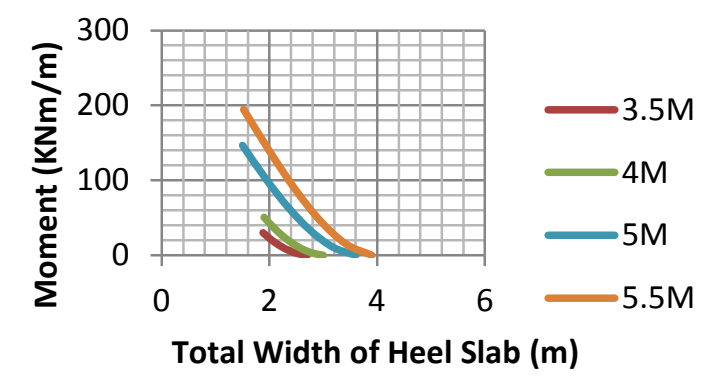

$(\mathrm{g})$

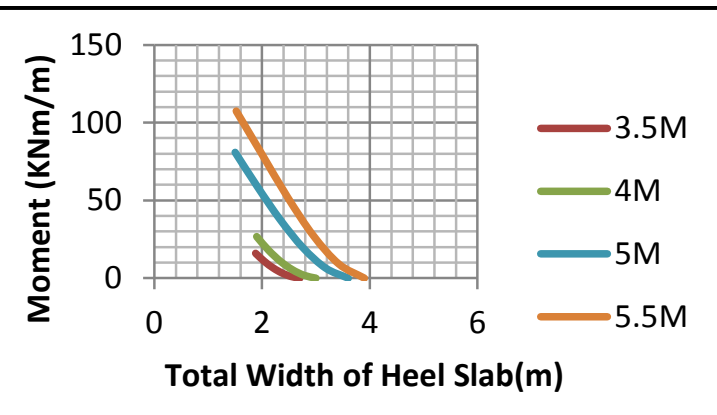

(b)

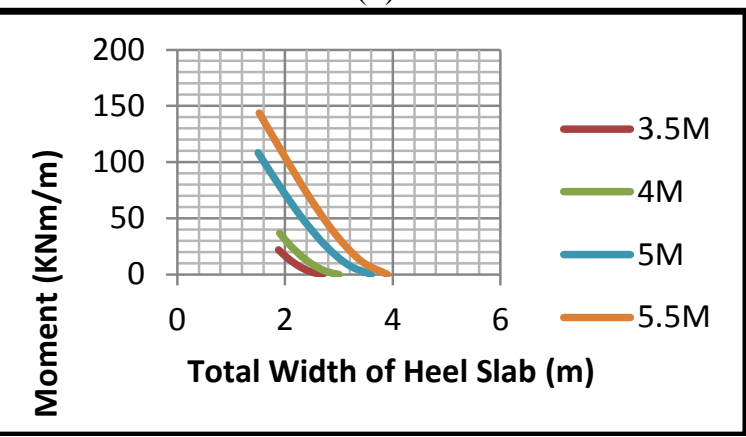

(d)

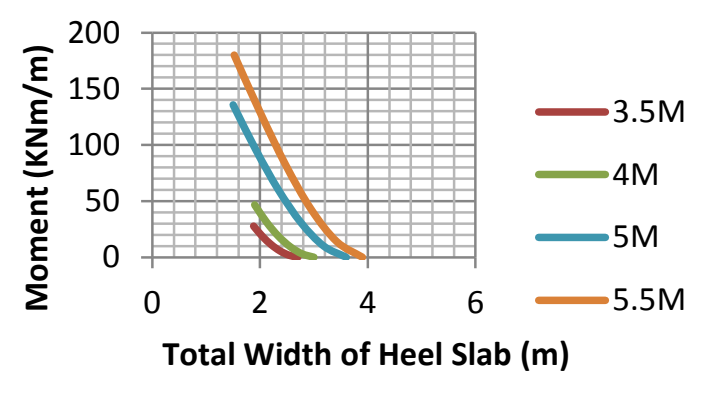

(f)

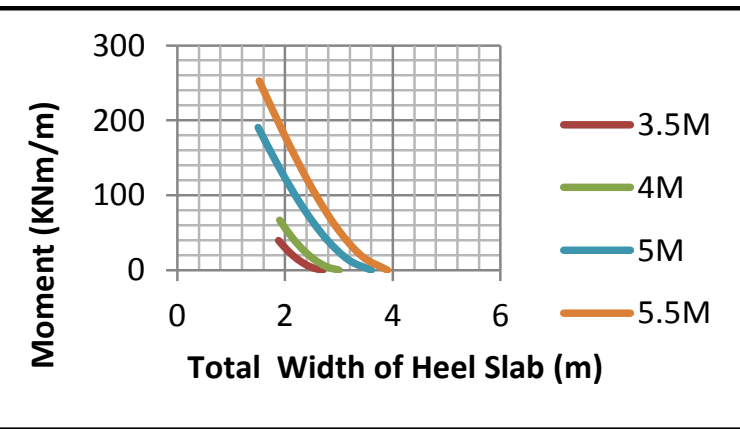

(h)

Fig: 5Moment v/s Total Width of Heel Slabaccording to table.1

The graph present variation of moment in heel slab according to changing height of the stem and the backfill having same density in fig.(a) to fig.(h), the density varies $18 \mathrm{KN} / \mathrm{m}^{3}$ to $40 \mathrm{KN} / \mathrm{m}^{3}$.Its Show the variation based on heel slab width varying when height of stem increased and also moment increased. Based on the graph the percentage steel required easily measured and the quantity of steel based on optimum is find out.

b) Moments and shears along toe of base slab

The toe slab will bend upwards as a cantilever due to upward soil reaction. Hence reinforcement is placed at the bottom face. Normally, the thickness of both toe slab and heel slab is kept the same, determined on 
Evaluation of the effect of lateral soil pressure on cantilever retaining wall with soil type variation

the basis of greater of the cantilever bending moments. So that the distribution of moment according to length and the variation of shear force may be calculated and represented by the graph

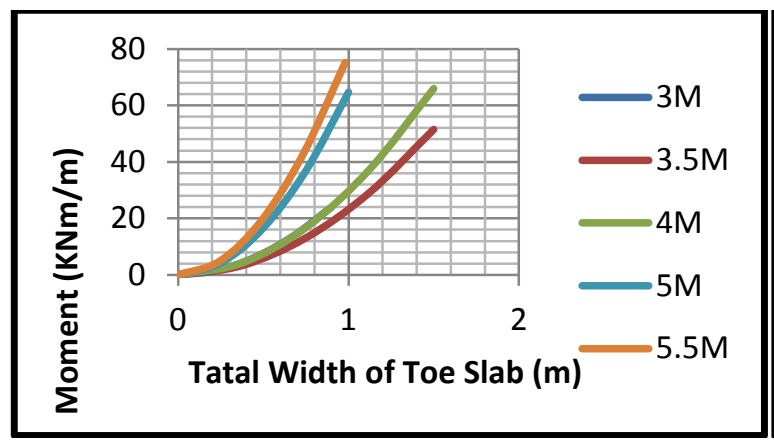

(i)

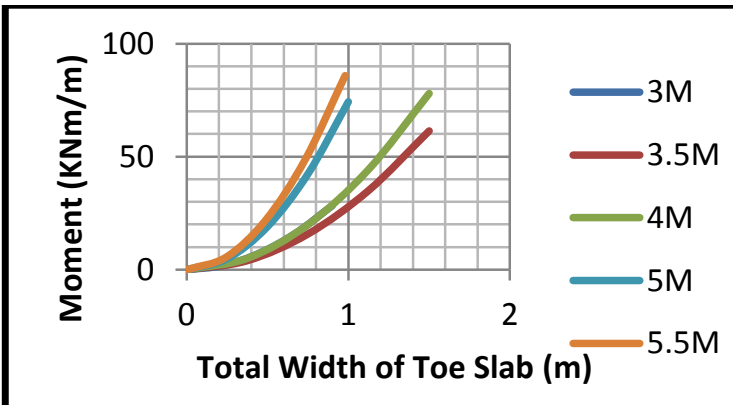

(k)

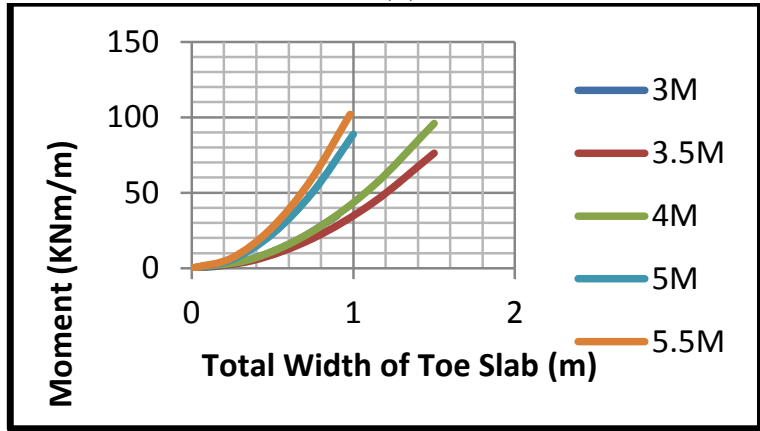

(m)

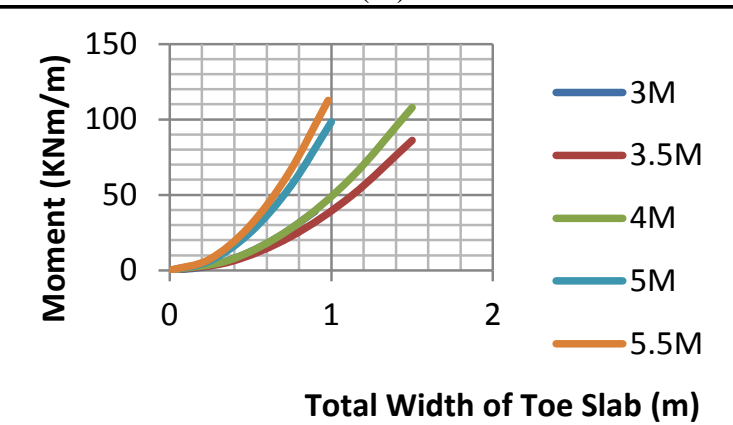

(o)

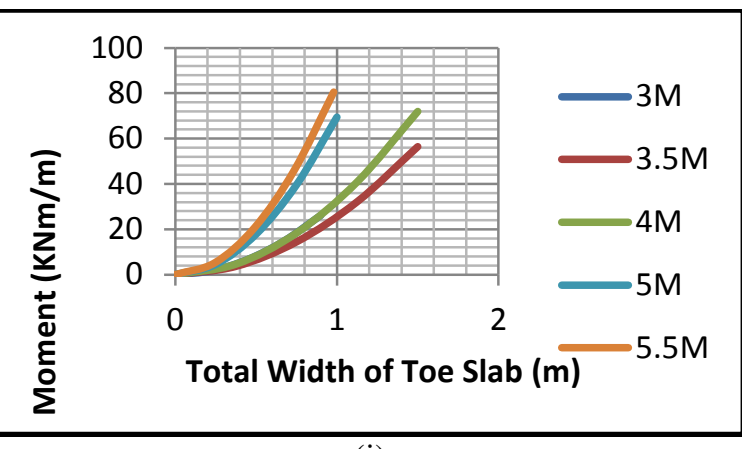

(j)

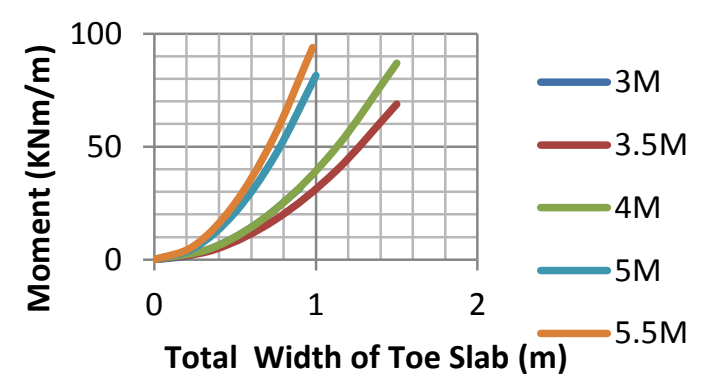

(1)

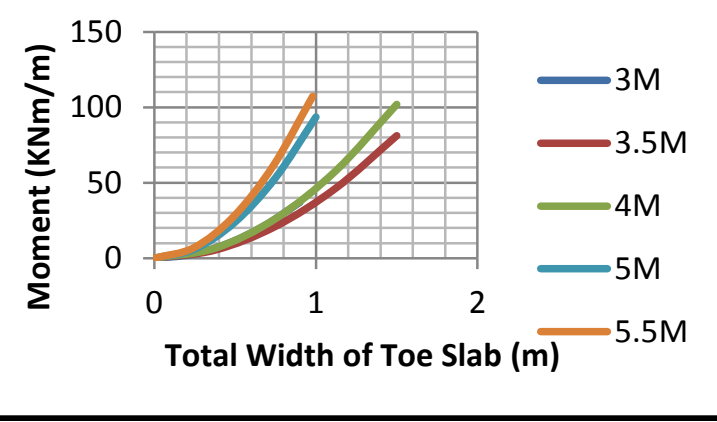

(n)

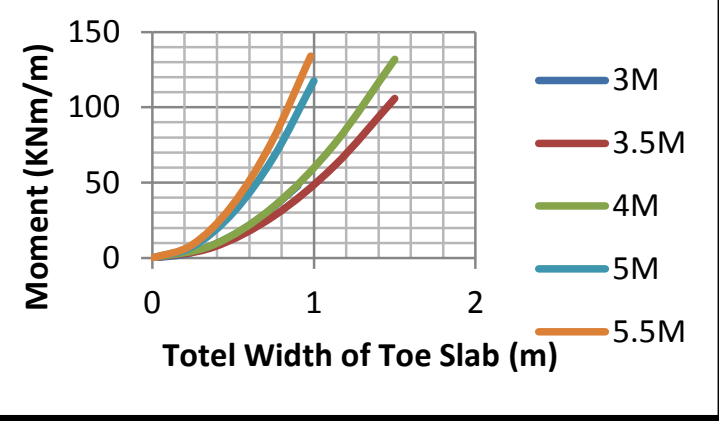

(p)

Fig: 6Moment v/s Total Width of Toe Slab according to table.1

Similarly, the graph present variation of moment in toe slab according to changing height of the stem and the backfill having same density in fig. (a) to fig.(h), the density varies $18 \mathrm{KN} / \mathrm{m}^{3}$ to $40 \mathrm{KN} / \mathrm{m}^{3}$. Its Show the variation based on heel slab width varying when height of stem increased and also moment increased. Based on the graph the percentage steel required easily measured and the quantity of steel based on optimum is find out. 


\section{CONCLUSION}

The analysis \& computing are done for many sections that satisfy the check conditions and displaying the dimension of the corresponding section and the steel requirement in these sections. The practical approach of design of a retaining wall has been kept in mind and the coding has been done to give a logical design. Based on the present study following conclusions are made.

1. It was observed that the calculated factor of safety against sliding is increasing when the density of back fill material is decreased. It shows that the resultant horizontal force affects the factor of safety against sliding and its allowable resistance.

2. The calculated factor of safety can be used in designing a retaining wall efficiently.

3. The calculated FOS against sliding is providing the bench mark to analysis.

4. The resultant overturning moment increases if the density of material is increased. It shows that distribution of load happens in a triangular pattern.

\section{Journal Papers:}

\section{References}

[1]. M. Ghazavi and S. BazzazianBonab (2011). "Optimization of Reinforced Concrete Retaining Walls Using Ant Colony Method." ISGSR 2011 - Vogt, Schuppener, Straub \&Bräu (eds), BundesanstaltfürWasserbau ISBN 978-3-939230-01-4.

[2]. S., M., Shaid (2005). "Cantilever Retaining Wall Design and Analysis (Rcwall)." Thesis for Bachelor of Science, Mara University of Technology.

[3]. Anna Scotto di Santolo , Aldo Evangelista (2011). "Dynamic Active Earth Pressure on Cantilever Retaining Walls." Computers and Geotechnics 38, pp.1041-1051.

[4]. ZhifengLiu , C. HseinJuang and SezAtamturktur (2013). "Confidence Level-Based Robust Design Of Cantilever Retaining Walls In Sand." Computers and Geotechnics 52, pp.16-27.

[5]. BabuSivakumar G.L., Basha B.M.(2006), "Inverse Reliability Based Design Optimization of Cantilever Retaining Walls." 3rd International ASRA Net Colloquium, 10th-12th July, Glasgow, UK: pp 3-7.

[6]. Jaky, J. (1944). "The coefficient of earth pressure at rest." J. Soc. Hung. Eng. Arch, 355-358.

[7]. Bentler J.G., Labuz, J. F. (2006).“Performance of a cantilever retaining wall.” Journal of geotechnical and geoenvironmental engineering. 132: 1062-1070.

[8]. Clough G. W., Duncan J.M. (1971).“Finite element analyses of retaining wall behavior.” Journal of geotechnical engineering. 97: 1657- 1673

[9]. Duncan J.M., Clough G. W., Ebeling, R.M. (1990).“Behavior and design of gravity earth retaining structures.” Invited contribution to the ASCE conference design and performance ofearth retaining structures, cornell, $\mathrm{N} \mathrm{Y}$

[10]. IS:14458 (part2) :1997: Retaining wall for hill area -guidelines, (Part2: design of Retaining wall)

[11]. Clauses from Indian Standard, "IS 456:2000", Bureau of Indian Standards, pp 34-49, pp 67- 76, July 2000.

Books:

[12]. Fendon G.A. and Griffiths. D.V. (2008). Risk assessment in geotechnical engineering. John Wiley \& Sons.

[13]. Pillai S.U. and Menon D., Reinforced Concrete Design, New Delhi: Tata McGraw-Hill Publishing Company Limited, 2nd Edition 2003.

[14]. Punmia B.C., Ashok Kumar Jain, Arun Kumar Jain, R.C.C. Designs, New Delhi: Laxmi Publications (P) Ltd, 10th Edition 2006.

[15]. Murthy, V.N.S. (2003). Geotechnical Engineering: Principles and Practices of Soil Mechanics and Foundation Engineering, CRC Press.

[16]. Clayton C.R.I., Milititsky J., Woods R.I.,(1993). "Earth Pressure and Earth Retaining Structures", Spon Press, Taylor and Francis Group, 2nd Edition 1993, , pp. 155-161. 